\title{
Further Problems with Projectivism
}

\section{THOMAS PÖLZLER}

\section{Department of Philosophy, University of Graz, Austria}

\begin{abstract}
From David Hume onwards, many philosophers have argued that moral thinking is characterized by a tendency to "project" our own mental states onto the world. This metaphor of projection may be understood as involving two empirical claims: the claim that humans experience morality as a realm of objective facts (the experiential hypothesis), and the claim that this moral experience is immediately caused by affective attitudes (the causal hypothesis). Elsewhere I argued in detail against one form of the experiential hypothesis. My main aim in this paper is to show that, considering recent psychological studies about folk metaethics and the relation between moral judgements and emotions, the causal hypothesis must be considered problematic too. First, the most common argument in favor of the causal hypothesis is based on an implausible premise and a dubious assumption. Second, ordinary people's moral experience is influenced by a non-affective factor, namely their openness to divergent moral views. And third, projectivism in general and its causal hypothesis in particular might not even hold true for affective moral judgements. This negative assessment of projectivism is significant both for our understanding of moral cognition as an empirical phenomenon and for metaethics.
\end{abstract}

KEY WORDS: moral projectivism; moral experience; moral psychology; experimental philosophy

In the $17^{\text {th }}$ century various philosophers began to entertain the idea that humans' experience of certain kinds of facts as objective is not due to their perceiving these facts; rather, they "project" their own mental attitudes onto the world. Besides colors, sounds, taste (Locke [1690] 1997) or causality (Hume [1740] 1978), this projectivist hypothesis was mainly advocated with regard to morality. The most prominent early defender of moral projectivism was David Hume. In his "Enquiry Concerning the Principles of Morals", Hume famously claimed that the human capacity of "taste" (which he took to include morality) "gilds and stains" the objective world: 
$[\ldots]$ taste $[\ldots]$ has a productive faculty, and gilding and staining all natural objects with the colours, borrowed from internal sentiment, raises in a manner a new creation. (Hume [1751] 1983: p. 88)

Today moral projectivism still enjoys considerable popularity (e.g., Mackie [1977] 2011; Blackburn 1993; Greene 2002; Joyce 2009, 2010). Simon Blackburn, one of the view's most prominent defenders, explains:

We have sentiments or other reactions caused by natural features of things and we "gild or stain" the world by describing it as if it contained features answering to these sentiments, in the way that the niceness of an ice cream answers to the pleasure it gives us. (Blackburn 1993: p. 152)

Moral projectivism is often thought of as entailing the metaethical view of anti-realism; i.e., it is assumed that the objective moral properties that humans are led to attribute to things do not actually exist (D'Arms and Jacobson 2006: p. 188; Kauppinen 2013: p. 14). However, one may also advocate or discuss only the empirical core of claims of projection (Joyce 2009: p. 57). In this minimal, metaethically uncommitted sense moral projectivism has sometimes been claimed to support moral anti-realism rather than being defined by it. For example, some metaethicists have argued that projectivism weakens or defeats the prima facie reason in favor of realism (supposedly) generated by our realist-seeming moral experience (see Mackie [1977] 2011: p. 42; Greene 2002: pp. 143-144), or that it provides evidence in favor of error theory's semantic claim of objectivist cognitivism (see Mackie [1977] 2011: pp. 33-35; Joyce 2009: p. 59). So is minimal moral projectivism (henceforth simply "projectivism") true?

How one assesses the plausibility of projectivism significantly depends on what one means by humans "projecting" their mental states onto the world. Following Richard Joyce, Section 1 explains that the metaphor of projection may be understood as involving two claims: the claim that humans experience morality as a realm of objective facts (the experiential hypothesis), and the claim that this moral experience is immediately caused by affective attitudes (the causal hypothesis). Elsewhere I argued in detail against one form of the experiential hypothesis (Pölzler 2014: pp. 70-120, forthcoming). My aim in this paper is to strike another blow against projectivism. Considering recent psychological studies about folk metaethics and the relation between moral judgements and emotions, I attempt to show that projectivism's causal hypothesis must be deemed problematic too. My argument consists of three parts. In Section 2 I shall argue that the most common argument in favor of the causal 
hypothesis is based on an implausible premise and a dubious assumption. In Section 3 I shall argue that ordinary people's moral experience is influenced by a non-affective factor, namely their openness to divergent moral views. And in Section 4 I shall argue that projectivism in general and its causal hypothesis in particular might not even hold true for affective moral judgements.

\section{Clarifications}

According to projectivism, moral cognition is characterized by humans "projecting" their own mental states onto the world. It is important to note that this claim is metaphoric. None of its proponents believe that, like in cases of literal projection, certain kinds of mental states emanate from our minds and cover parts of the world (D'Arms and Jacobson 2006: p. 188; Joyce 2009: p. 60). In order to be able to assess projectivism's plausibility we must therefore translate it into more literal terms. In this paper I assume a conception of projectivism that has recently been developed by Richard Joyce (2009 and 2010), and has in identical or similar forms also been endorsed by various other participants of the debate (e.g., Greene 2002: 146147; Kail 2007: 3-4; Olson 2014: p. 6). On Joyce's view, projectivism is essentially a "causal account of moral experience" (2007b). As such, it involves two claims: a claim about the nature of humans' moral experience, and a claim about the causes of this experience.

With regard to the nature of our moral experience projectivists hold that this experience is realist-seeming, i.e., that humans experience morality as objective.

\section{The Experiential Hypothesis ${ }^{l}$ :}

Humans experience morality as a realm of objective facts (see Joyce 2009: pp. 60-68).

As projectivists typically understand this claim, humans experiencing morality as "objective" means that they experience morality as "out there": as something that exists in the world, and waits to be discovered. Joyce specifies this idea in terms of subject-independence (2009: pp. 62-65 and fn. 3). Morality would qualify as objective in this sense if and only if whether things are right, wrong, good, bad, etc. is independent from one's own (i.e., the subject's)

\footnotetext{
${ }^{1}$ Joyce refers to this hypothesis as "phenomenological". For reasons that will become clear soon, this label is somewhat misleading.
} 
mental states - from how one feels about these things, what one believes about them, and so forth. ${ }^{2}$

The experiential hypothesis' notion of "experience" is most readily understood in an exclusively phenomenological sense. Projectivists seem to be committed to the view that "what it is like" to make moral judgements is to respond to moral facts that are independent from us. However, Joyce rightly emphasizes that in the present context "experience" is more appropriately understood in a broader sense (2009: pp. 65-66). While some projectivists may hold views about the qualitative character of moral judgements, some may also only mean that humans have a deeply entrenched metaethical intuition that morality is objective - an intuition that may or may not have any qualitative character.

In addition to its claim about the nature of humans' moral experience, projectivism also entails a claim about how this experience comes about. In particular, it entails that what causes us to experience things as objectively right, wrong, good, bad, etc. is not that we perceive them to have these properties, but rather a kind of mental attitudes within us, namely affective attitudes. Suppose, for example, you witness some kid torturing puppies for fun. Your observation may arouse certain negative affective attitudes in you: emotions like anger or disapproval, say. According to projectivism's causal hypothesis, it is these affective attitudes that then cause you to have the experience that torturing puppies for fun is objectively wrong.

\section{The Causal Hypothesis:}

Humans' moral experience is immediately caused by affective attitudes (see Joyce 2009: pp. 68-69). ${ }^{3}$

Projectivists have said little about what they mean when they talk of (particular) "affective attitudes" causing humans' moral experience. There are reasons to believe, however, that their conception of these attitudes is non-cognitivist, i.e. that they conceive of the attitudes as lacking any cognitive content and hence as not representing facts. First, in line with Joyce's above

\footnotetext{
${ }^{2}$ Note that in contrast to many other conceptions of objectivity (e.g., Huemer 2005: pp. 2-4), this subjectindependence conception allows for morality to be objective relative to some subjects, but subjective relative to others. Joyce illustrates this by an analogy with a person's sadness. While my sadness is subjective from my own perspective (it trivially depends on my own mental states), for anybody else it is something that is "out there" and can be discovered (2009: pp. 63-64).

${ }^{3}$ Projectivists need not claim that perceptions do not play any role whatsoever in generating ordinary people's moral experience. For example, they may acknowledge that our seeing a certain action often causes us to have the emotions that then lead us to have a certain moral experience. Hence the qualification "immediate" (Joyce 2010: p. 39).
} 
explanations, projectivists generally contrast the relevant affective attitudes with perceptions, which are the products of a cognitive faculty (e.g., Hume 1978: pp. 468-469; Greene 2002: pp. 146-147). Second, some projectivists have explicitly characterized these attitudes as noncognitive. Simon Blackburn, for example, explains that the attitudes that humans tend to project onto the world are "not descriptive" (1984: p. 171). And third, as almost all proponents of projectivism hold metaethical positions according to which there are neither objective nor subjective (robust) moral facts (see, e.g., Blackburn 1984; Joyce 2001; Mackie [1977] 2011), there is no metaethical reason for them to construe the relevant affective attitudes as cognitive (and thus possibly responsive to moral facts) either.

Projectivism's commitment to the non-cognitivist character of the attitudes appealed to in its causal hypothesis has important, yet widely neglected implications for the assessment of this hypothesis (McNaughton 1988: p. 113). It entails that the causal hypothesis cannot only be refuted by showing humans' moral experience to be caused by cognitive attitudes, but also by establishing that the particular affective attitudes that this hypothesis appeals to involve significant cognitive elements. A refutation of this second (more theoretical and conceptual) kind seems prima facie plausible with regard to at least some kinds of affective attitudes, such as, for example, emotions (see, e.g., Lazarus 1991; Solomon 1993; Nussbaum 2004). In what follows, however, I will grant projectivists that the emotions, sentiments, passions or other affective attitudes that they appeal to are non-cognitive, and rather focus on the first of the above mentioned refutations.

Granting projectivists their conception of affective attitudes, the truth of projectivism becomes a largely empirical question. Questions of this kind are most reliably assessed by the methods of empirical science. In recent years various projectivists have argued that the available scientific evidence strongly supports their view. Richard Joyce, for example, claims that "evidence concerning (on the one hand) what really causes moral judgement and (on the other hand) how it seems to us virtually adds up to a statement of moral projectivism" (2007a: p.125). And according to Joshua Greene, projectivism has recently "gained widespread acceptance among experimental psychologists" (2002: p. 142). In the following three sections I will argue that with regard to projectivism's causal hypothesis this assessment is likely wrong. Recent psychological research on folk metaethics and the relation between moral judgements and emotions suggests that humans' moral experience is the product of cognitive rather than affective attitudes. 


\section{The Argument from Emotionism}

Projectivism's causal hypothesis has recently typically been defended by appeal to the claim that moral judgements are mainly caused by emotions (see Greene 2002: p. 142; Joyce 2007a: p. 130). In what follows I will show that this "emotionist" argument in favor of projectivism's causal hypothesis is weak. First, the claim that moral judgements are mainly caused by emotions is contradicted rather than supported by the available scientific evidence. ${ }^{4}$ And second, even if this claim were true, it would not lend (much) support to the hypothesis that humans' moral experience is mainly caused by emotions anyway.

\section{Moral Judgements and Emotions}

The claim that moral judgements are mainly caused by emotions has recently become quite popular (see, e.g., Haidt 2001; Greene and Haidt 2002; Prinz 2006, 2007b). Among others, it has been thought to be supported by two studies about the effect of disgust. In the first study (Schnall et al. 2008a) one group of subjects was confronted with stimuli likely to make them feel disgusted (e.g., they were seated in a room treated with "fart spray" or asked to recall a physically disgusting experience), while another group was not confronted with these stimuli. When subjects were then asked to rate the moral wrongness of a number of actions it turned out that those in the disgust conditions rated the actions significantly more wrong than those in the neutral conditions - or at least this is how the study's results are often presented (e.g., Prinz 2006: p. 31).

Subjects in the second study (Schnall et al. 2008b) had to watch a film clip that involved a dirty toilet. One group was then asked to complete an otherwise unrelated task involving words associated with cleanliness, for example "pure", "clean", or "pristine", or to wash their hands with soap and water. The other group completed a task involving only neutral words, or were not given the opportunity to wash their hands. Again disgust, or the absence of it, seemed to have had a significant influence of subjects' moral judgements. Those in the cleanliness conditions rated thee actions they were presented with significantly less wrong than those in the neutral conditions - or again, this is at least how the results of the study are often presented (e.g., Prinz 2011: p. 137).

\footnotetext{
${ }^{4}$ This part of the Section is based on Pölzler 2015: pp. 181-184.
} 
As shown in Pölzler 2015 (pp. 183-184), there are two main problems with the above interpretation of Schnall et al.'s studies. ${ }^{5}$ The first problem is methodological. Although the studies' findings may be explained by disgust (or other emotions) influencing subjects' moral judgements, they are consistent with various alternative explanations as well. For example, emotions may have influenced subjects' perception of the actions they were presented with rather than their moral judgements (e.g., they may have increased their awareness of the actions having certain morally relevant non-moral features, see Huebner et al. 2009: pp. 1-3); or subjects may rather have become aware of their having the emotion they were induced to have, and this awareness affected their reasoning (e.g., they may have (unconsciously) reasoned that because they felt disgust, there had to be something wrong with the action at issue, even though they could not tell what it was, see Jones 2006: p. 50).

The second main problem with many commentators' interpretation of the above studies is that they have grossly exaggerated these studies' results (see May 2014). Proponents of the significance of emotions in moral judgements have often suggested that in these studies, emotions affected the severity of subjects' moral judgements with regard to all or most of the scenarios they were presented, and to a rather strong degree. But this is clearly wrong. In the first above study only the first of four experiments showed a significant effect of disgust that was independent from subjects' awareness of changes in their body (Schnall et al. 2008a: 11001103). And even in this first experiment disgust only made subjects' judgements significantly harsher with regard to 2 out of 4 vignettes in the weak and 1 out of 4 vignettes in the strong experimental condition, and only to an average of 0.6 on a seven-point scale of wrongness (Schnall et al. 2008a: 1099).

Similar considerations apply to the second study as well. Coming across cleanliness words/handwashing had a significant effect on subject's wrongness ratings only with regard to 1 out of 6 of the scenarios presented in experiment 1 , and 2 out of 6 of the scenarios of experiment 2. Moreover, the effect was again quite small. On the nine-point wrongness scale of experiment 1 subjects in the non-disgust condition rated actions at an average of 4.98, and subjects in the disgust condition at 5.81 (Schnall et al. 2008b: 1220). On the seven-point wrongness scale of experiment 2 , subjects in the non-disgust condition rated the actions at an average of 4.73, and subjects in the disgust condition at 5.43 (Schnall et al. 2008b: 1221).

\footnotetext{
${ }^{5}$ Note that Schnall et al. themselves do not endorse the above interpretations. They present their data in a more cautious way.
} 
Reviews and meta-analyses by Landy and Goodwin (2014), May (2014), Pizzaro et al. (2011) and others suggest that, at least on closer consideration, most other relevant studies are in line with those considered above. They too suggest that emotions often do not have any substantial effect on moral judgements. Moreover, the conclusion that moral judgements are not mainly caused by emotions is also supported by studies on the co-occurrence of moral judgements and emotions. In Greene et al.'s (2001) famous Trolley dilemma study, for example, subjects were presented various moral dilemmas that either involved inflicting harm in a personal or impersonal way. It turned out that when subjects thought about impersonal moral dilemmas they showed very little activity in brain areas typically associated with emotions (Greene et al. 2001: p. 2107). However, if (significant) emotional activity does not even correlate with particular kinds of moral judgements, then it cannot be these judgements' predominant cause either.

\section{Moral Judgements and Moral Experience}

My second main objection against the emotionist argument in favor of projectivism's causal hypothesis concerns this argument's inductive strength. Moral judgements and moral experiences are distinct aspects of moral cognition. The truth of the claim that moral judgements are mainly caused by emotions would therefore not entail that our moral experience is mainly caused by emotions too. In order for the causal hypothesis to be supported by this claim it would also have to be the case that our moral judgements and our moral experience are causally regulated by one and the same mental attitude. For example, as apparently assumed by Joyce (2009: p. 70), the same attitude would have to cause us first to have a particular moral experience and then, via this experience, to make a corresponding moral judgement. Let us call this assumption of the emotionist argument in favor of the causal hypothesis the "same attitude assumption".

Suppose the same attitude assumption were true. In this case we should find all sorts of correlations between people's moral judgements and their moral experiences. Most obviously, we should find a correlation between the strength with which people hold a moral judgement and the kind of moral experience they have with regard to it. The stronger a person's confidence in her judgement that a thing is right, wrong, good, bad, etc., the more likely she should be to experience this thing's rightness, wrongness, goodness, badness, etc. as an objective property of that thing (Goodwin and Darley 2010: p. 180). Is this implication of the same attitude assumption true? 
In recent years psychologists have become increasingly interested in ordinary people's metaethical intuitions (e.g., Goodwin and Darley 2008, 2010; Wright et al. 2013, 2014). Elsewhere (Pölzler forthcoming) I argue that several prominent studies on this issue did not measure what they attempted to measure. Most commonly, they confused the question of whether moral judgements purport to represent (objective) moral facts (cognitivism vs. noncognitivism) with the question of whether these facts exist (realism vs. anti-realism). I therefore suggested reinterpretations of these studies which I will also assume in what follows. Regardless of whether one tends towards these reinterpretations or the experimenters' original interpretations, however, it seems that the available data with regard to the same attitude assumption is ambiguous or rather contradicts this assumption.

One early study on folk metaethics, conducted by Goodwin and Darley (2008), is consistent with the same attitude assumption's prediction of a correlation between persons' strength of agreement to moral judgements and their metaethical intuitions. Subjects in this study who responded as cognitivists to a particular moral statement (which entails realism or some, but not all forms of anti-realism) tended to agree significantly stronger to this statement than subjects who responded as non-cognitivists to it (which is a variant of anti-realism) (Goodwin and Darley 2008: pp. 1350, 1354). Two other relevant studies did not find any such correlation, though.

Consider, first, a recent study by Wright, Grandjean and McWhite (2013). In this study subjects' metaethical intuitions were determined by asking them two questions. Properly interpreted, subjects' responses to these questions are indicative of either more cognitivist and realist leanings or more non-cognitivist and anti-realist leanings. It turned out that subjects who chose the more cognitivist and realist option with regard to a moral statement did not tend to agree with it more strongly than subjects who chose the more non-cognitivist and antirealist option (see Wright et al. 2013: pp. 342, 344):

[...] while a wealth of research has found that people treat differently those attitudes and beliefs they hold strongly from those they hold more weakly [...], attitude strength did not reveal itself here to be predictive of [...] objectivity. (Wright et al. 2013: p. 342)

Second, Goodwin and Darley decided to have another look at the relation between metaethical intuitions and strength of agreement as well. This time they did not find a correlation either (reported in 2010: p. 180): 
$[\ldots]$ our data has shown that $[\ldots]$ objectivity judgments are divergent from first order moral judgments, i.e., they are divergent from strength of agreement ratings concerning moral beliefs. (Goodwin and Darley 2010: p. 180)

The available evidence on the relation between the strength of people's moral judgements and their metaethical intuitions is admittedly scarce. As shown above, however, it provides at least some reason to believe that the emotionist argument's same attitude assumption may be false. This argument is thus not only based on an implausible premise, its inductive strength rests on a shaky foundation too. Even if moral judgements were mainly caused by emotions, this may not lend (much) support to the claim that our moral experience is mainly caused by emotions as well.

\section{The Causes of Metaethical Intuitions}

In section 2 I showed that projectivists' main argument for their causal hypothesis is weak. In addition, there is also positive evidence for doubting that humans' moral experience is immediately caused by affective attitudes.

Several psychologists and philosophers have recently suggested that ordinary people's metaethical intuitions are at least in part determined by their openness to alternative moral views. The more one is able and willing to consider the perspective of others with regard to a certain moral issue (for example, the more one is able and willing to imagine how one would judge this issue if one had others' interests, desires, world-views, etc.), the more anti-realist one's metaethical intuitions with regard to this issue become (Sarkissian et al. 2011: p. 501). ${ }^{6}$ The truth of this hypothesis about the causes of our metaethical intuitions would clearly be bad news for projectivists. As being open to alternative perspectives essentially involves reasoning about the implications of different possibilities and is therefore likely a predominantly cognitive factor (see Goodwin and Darley 2010: p. 180), it would mean that humans' moral experience is not exclusively determined by affective reactions.

In this Section I will argue that the hypothesis that humans' moral experience is causally influenced by their openness to divergent moral perspectives is indeed plausible. First, I will present three studies that suggest a strong correlation between ordinary people's metaethical

\footnotetext{
${ }^{6}$ Another variable that was found to significantly correlate with and even to some degree causally influence people's metaethical intuitions is people's perceptions of consensus. The wider subjects believed a statement to be accepted by others, the more cognitivist/realist their responses turned out to be (Goodwin and Darley 2012: pp. 253-254).
} 
intuitions and their openness to alternative moral perspectives. And second, I will argue that this correlation is at least in part to be explained by the hypothesis that people's openness to alternative moral perspectives causally influences their metaethical intuitions.

\section{Verbal Explanations}

First evidence for a correlation between persons' metaethical intuitions and their openness to alternative moral perspectives is provided by Goodwin and Darley's above 2008 study. Subjects in this study were told that another subject had denied a moral judgement that they themselves had previously made. Then they were (among others) asked why they believed this disagreement might have arisen (2008: p. 1363). It turned out that answers to this question correlated with subjects' metaethical intuitions. Those who had been drawn towards more cognitivist and realist options tended to express surprise about how anybody could disagree with them and tended to characterize the other subject as morally depraved. With regard to the statement "Robbing a bank in order to pay for an expensive holiday is a morally bad action," for example, some more cognitivist and realist subjects explained such disagreements as follows: "The other person obviously has no values, and no respect for the property of others!" "The other person has a warped view of what is a moral action." (Goodwin and Darley 2010: p. 174) Subjects who tended towards non-cognitivism and anti-realism, in contrast, rather tried to understand and make sense of the disagreeing persons' judgements (Goodwin and Darley 2010: p. 174).

\section{Tolerance}

Further evidence for a correlation between persons' metaethical intuitions and their openness to alternative moral perspectives comes from a recent study by Wright, McWhite, and Grandjean (2014). Subjects in this study were again told that another person disagreed with one of their moral judgements. Then their degree of tolerance for this person's divergent moral view was examined. For example, subjects were asked how willing they would be to interact with this person, how willing they would be to help him/her, or how comfortable they are with another person denying one of their moral judgements in general (2014: pp. 35, 43). Wright et al. found that in all of these respects subjects with more cognitivist and realist leanings were significantly less tolerant towards the disagreeing person's moral views than subjects who had tended towards non-cognitivism and anti-realism (2014: pp. 37, 46). 


\section{Disjunctive Reasoning}

A last relevant study was again conducted by Goodwin and Darley (2010). Subjects in this study were asked to complete the following psychological test:

There are five blocks in a stack, where the second one from the top is green and the fourth is not green. Is a green block definitely on top of a non-green block? [answers: "yes", "no", and "cannot tell"] (Goodwin and Darley 2010: p. 175).

In order to figure out the right answer to this question, one must be able to disentangle the possibilities with regard to the colour of the third block. In particular, one must consider what would follow if this block was green, and what would follow if it was not. The above task is thus widely used as a measure of people's "disjunctive reasoning ability": their ability to consider alternative possibilities when deciding between options. In their study Goodwin and Darley found that subjects' metaethical intuitions were significantly correlated to their performance in the above task. Subjects drawn to more cognitivist and realist options were significantly less able to solve the task than subjects drawn to more non-cognitivist and antirealist ones (2010: pp. 175-176).

All three of the above studies suggest a correlation between people's metaethical intuitions and their openness to alternative moral perspectives. One way in which this correlation has recently been explained is by the hypothesis that people's metaethical intuitions cause them to be more or less open to alternative moral perspectives (Wright et al. 2013, 2014). While this explanation may indeed capture part of the truth, there is reason to believe that causation (also) runs in the other direction, i.e., that persons' being more or less open to alternative moral perspectives causes them to have more or less realist intuitions. This interpretation of the data is in particular supported by Goodwin and Darley's Disjunctive Reasoning Ability experiment.

People's disjunctive reasoning abilities are rather stable personality traits (e.g., Toplak and Stanovich 2002) which possibly even have some heritable basis. ${ }^{7}$ Seeing moral issues in a more realist or anti-realist light therefore likely does not substantially causally influence these abilities. A more plausible explanation of the correlation found by Goodwin and Darley is that

\footnotetext{
${ }^{7}$ A study by Feltz and Cokely (2008) suggests that ordinary people's metaethical intuitions are correlated with another rather stable and possibly inherited trait associated with openness to alternative moral perspectives as well, namely with their openness to experiences.
} 
both people's disjunctive reasoning ability and their metaethical intuitions are regulated by some third factor. For example, it might be speculated that having a strong cognitive reflection ability or a strong need for cognition promotes both one's ability to reason disjunctively and the anti-realist character of one's metaethical intuitions. But the prospects of explanations of this kind are unclear as well. In their above study Goodwin and Darley, for example, found that several factors that may plausibly be claimed to influence people's metaethical intuitions (including their cognitive reflection ability and need for cognition) do not even correlate with these intuitions (2010: p. 175). This suggests that the correlation between people's disjunctive reasoning ability and their metaethical intuitions may at least partly be attributable to the fact that their disjunctive reasoning ability causally influences these intuitions (Goodwin and Darley 2010: 180).

In sum, while research about the causes of ordinary people's metaethical intuitions is still in its infants, it seems to provide at least some reason to believe that humans' moral experience is in part determined by their openness to alternative moral perspectives, which means that it is at least in part determined by a non-affective factor.

\section{Enabling Projectivism}

As projectivism is understood in this paper, it is the conjunction of two claims: the claim that humans experience morality as a realm of objective facts (the experiential hypothesis), and the claim that this moral experience is immediately caused by affective attitudes (the causal hypothesis). In the previous two sections I argued that in addition to the experiential hypothesis (Pölzler 2014: pp. 70-120, forthcoming), we have reason to be skeptical about the causal hypothesis as well. If this consistently negative assessment is correct, then it seems reasonable to reject projectivism and explain our moral experience in an alternative way. However, at least some philosophers would complain that such a conclusion would still be hasty.

So far projectivism has been addressed as a statistical hypothesis. It has been taken to claim that it is true for most ordinary people most of the time that they experience morality as a realm of objective facts, and that their moral experience is immediately caused by affective attitudes. This is how projectivism has most commonly been advocated. Recall, for example, the famous statements by Hume and Blackburn quoted in the introduction to this paper. Neither of them qualifies his projectivist hypothesis in any sense. At least one proponent of the view, however, namely Richard Joyce, has recently argued that projectivism need not and actually should not be understood in such a statistical sense. 
According to Joyce, projectivism turns out much more plausible if it is restricted to what he calls "privileged" moral judgements: moral judgements that are such that if one had never made them, it would be doubtful whether one has moral concepts and is able to make moral judgements at all (2007a: p. 132, 2009: pp. 69-73). This class of privileged moral judgements, Joyce suggests, coincides with the class of moral judgements that correlate with certain strong emotions. If a person has never made such "affective" moral judgements — if s/he has never judged something right, wrong, good, bad, etc. whilst feeling strong guilt, or empathy, for example - then the person does not fully understand what it means to say that something has these properties.

Can one make a moral judgment without any act of emotional projection involved? "Sure you can," says the Moral Projectivist. The Moral Projectivist might claim that this happens frequently, or even usually. What makes him nevertheless a Moral Projectivist is the conviction that there is a privileged category of moral judgment and the projectivist story is true of all (most of?) the members of that class. [...] If a person has never experienced the emotion of guilt, say, then they cannot really have the concept guilt. [...] grasp of these emotion/affect concepts is a necessary condition for being granted competence with the moral concepts. (Joyce 2009: pp. 71-73)

Joyce's "enabling projectivism" ("enabling" because it is based on the idea that affective moral judgements developmentally "enable" moral thinking) amounts to the conjunction of the following two hypotheses:

\section{The Experiential Hypothesis*:}

Humans experience morality as a realm of objective facts when they make affective moral judgements.

\section{The Causal Hypothesis*:}

Humans' moral experience is immediately caused by affective attitudes when they make affective moral judgements.

One first thing to note with regard to Joyce's qualification of projectivism is that in its enabling form projectivism can no longer ground most of the metaethical arguments that have been based on it. Both of the anti-realist arguments mentioned in the introduction, for example, require that ordinary people experience morality as objective and that this experience is 
immediately caused by emotions with regard to all or most moral judgements (Pölzler 2014: p. 283). From the perspective of some philosophers this implication of enabling projectivism will clearly reduce its attractiveness. Is enabling projectivism at least plausible as an empirical hypothesis, then? Do humans "project" their emotions onto the world when they make affective moral judgements? While there is too little evidence to answer this question in any decisive way, one can at least say that it is by no means obvious that enabling projectivism will turn out plausible.

Considering the results of some of the studies discussed above the experiential hypothesis' enabling version appears promising. Greene et al. (2001) showed that in contrast to moral judgements about impersonal harms, moral judgements about personal harms tend to be accompanied by strong emotional activity. If Joyce were right in that at least people's affective moral judgements were experienced in a realist way, we should therefore have such an experience when we make moral judgements about personal harms. And indeed, subjects in Goodwin and Darley's study (2008: pp. 1347, 1351) tended to rate moral sentences that involve rather personal inflictions of harm (e.g., sentences about the badness of opening gunfire on a crowded street or robbing a bank to pay for an expensive holiday) as more cognitivist and realist than rather impersonal moral sentences (e.g., sentences about the permissibility of stem cell research or abortion). ${ }^{8}$

The main problem with Joyce's attempt to rescue projectivism is that the causal hypothesis may be problematic in its enabling form too. In order for this hypothesis to be true it would have to be the case that our moral experience tends to be caused by affective attitudes when we make affective moral judgements. Judging from the studies considered in Section 3, however, this might not be the case. In these studies subjects' openness to alternative moral perspectives correlated with their metaethical intuitions and presumably influenced these intuitions with regard to moral judgements in general, including affective moral judgements. For example, a correlation between high degrees of cognitivist and realist intuitions and low openness for alternative moral perspectives was also found with regard to personal and thus presumably emotion-provoking sentences such as "Robbing a bank in order to pay for an ex-

\footnotetext{
${ }^{8}$ According to Greene et al., an action inflicts harm in a personal way if it "(a) could reasonably be expected to lead to serious bodily harm (b) to a particular person or a member or members of a particular group of people (c) where this harm is not the result of deflecting an existing threat onto a different party" (2001: 2107). Impersonal moral sentences, in contrast, involve actions that fail to meet at least one of these conditions. Needless to say, Greene et al.'s conception of the personal/impersonal distinction would need to be clarified much further. But at least on an intuitive level my above classifications seem reasonable. Whereas opening gunfire and robbery clearly fulfill (a) to (c), stem cell research and abortion at least seem to fail with regard to (b): these actions' victims are not yet (full) persons, at least not in a concrete, definable sense.
} 
pensive holiday is a morally bad action" (Goodwin and Darley 2010: p. 174). As openness to alternative moral perspectives is a cognitive factor, this finding raises the suspicion that not even moral experiences that accompany affective moral judgements may be exclusively brought about by affective attitudes.

\section{Conclusion}

From David Hume onwards, many philosophers and psychologists have argued that moral thinking is characterized by a tendency to "project" our own mental states onto the world. This metaphor of projection may be understood as involving two claims. Having criticized the first claim at other occasions (Pölzler 2014: pp. 70-120, forthcoming), this paper focused on the second. In particular, I argued that it is implausible that humans' moral experience is immediately caused by affective attitudes. First, the most common argument in favor of the causal hypothesis is based on an implausible premise and a dubious assumption. Second, humans' moral experience is influenced by a non-affective factor, namely their openness to alternative moral perspectives. And third, projectivism in general and its causal hypothesis in particular might not even be rescued by restricting them to affective moral judgements.

My above arguments are based on a small and to some extent controversial set of scientific evidence. They may therefore have to be adjusted or revised in the light of future findings. If it turned out true that projectivism ought to be rejected, however, this result would not only be significant for our understanding of moral cognition as an empirical phenomenon, but also for metaethics. It would suggest that any projectivist argument in favor of metaethical claims such as moral anti-realism is doomed, and would accordingly play in the hands of those who hold alternative claims. ${ }^{9}$

\footnotetext{
${ }^{9}$ This article is based on my PhD thesis in Philosophy. For helpful comments I would like to thank Johann Marek (my doctoral advisor) as well as an anonymous reviewer of the South African Journal of Philosophy.
} 


\section{References}

Blackburn, S. 1984. Spreading the Word. New York: Oxford University Press.

Blackburn, S. 1993. 'Errors and the Phenomenology of Value', in: Blackburn, S. (ed.). Essays in Quasi-Realism. New York: Oxford University Press, pp. 149-165.

D’Arms, J. \& Jacobson, D. 2006. 'Sensibility Theory and Projectivism', in: Copp, D. (ed.). The Oxford Handbook of Ethical Theory. Oxford: Oxford University Press, pp. 186-218.

Feltz, A, Cokely, E.T. 2008. 'The fragmented folk: More evidence of stable individual differences in moral judgments and folk intuitions', in: Love, B.C., McRae, K. \& Sloutsky, V.M. (eds.). Proceedings of the 30th Annual Conference of the Cognitive Science Society. Cognitive Science Society, pp. 1771-1776.

Goodwin, G.P. \& Darley, J.M. 2008. 'The psychology of meta-ethics: Exploring objectivism', Cognition 106(3), pp. 1339-1366.

Goodwin, G.P. \& Darley, J.M. 2010. 'The perceived objectivity of ethical beliefs: Psychological findings and implications for public policy', Review of Philosophy and Psychology 1(2), pp. 161-188.

Greene, J.D. 2002. The Terrible, Horrible, No Good, Very Bad Truth about Morality and What to Do About It. Princeton University: Ph.D. Thesis.

Greene, J.D. \& Haidt, J. 2002. 'How (and where) does moral judgment work?', Trends in Cognitive Sciences 6(12), pp. 517-523.

Greene, J.D., Sommerville, B.R., Nystrom, L.E.; Darley, J.M. \& Cohen, J.D. 2001. 'An fMRI investigation of emotional engagement in moral judgment', Science 293(5537), pp. 21052108 .

Haidt, J. 2001. 'The emotional dog and its rational tail: A social intuitionist approach to moral judgment', Psychological Review 108(4), pp. 814-834.

Huebner, B., Dwyer, S., Hauser, M.D. 2009. ,The role of emotion in moral psychology', Trends in Cognitive Science 13(1), pp. 1-6.

Huemer, M. 2005. Ethical Intuitionism. Basingstoke: Palgrave MacMillan.

Hume, D. [1740] 1978. A Treatise of Human Nature. Oxford: Clarendon Press.

Hume, D [1751] 1983. An Enquiry Concerning the Principles of Morals. Indianapolis: Hackett. 
Jones, K. 2006. 'Metaethics and emotions research: A response to Prinz', Philosophical Explorations 9(1), pp. 45-53.

Joyce, R. 2001. The Myth of Morality. Cambridge: Cambridge University Press.

Joyce, R. 2007a. The Evolution of Morality. Cambridge \& London: The MIT Press.

Joyce, R. 2007b. 'Projectivism and quasi-realism. Supplement to moral anti-realism', in: Zalta, E.N. (ed.). The Stanford Encyclopedia of Philosophy. http://plato.stanford.edu/entries/moral-anti-realism/projectivism-quasi-realism.html [201412-03].

Joyce, R. 2009. 'Is moral projectivism empirically tractable?', Ethical Theory and Moral Practice 12(1), pp. 53-75.

Joyce, R. 2010. 'Patterns of Objectification', in: Joyce, R. \& Kirchin, S. (eds.). A World without Values: Essays on John Mackie's Moral Error Theory. Dordrecht: Springer, pp. 35-54.

Kail, P.J.E. 2007. Projection and Realism in Hume's Philosophy. Oxford: Oxford University Press.

Kauppinen, A. 2013. 'Sentimentalism', in: LaFollette, H. (ed.). International Encyclopedia of Ethics. Oxford: Wiley-Blackwell. http://philpapers.org/rec/KAUSIE.pdf [2014-03-22].

Landy, J.F., Goodwin, G.P. 2014. 'Does incidental disgust amplify moral disgust? A metaanalytic review of experimental evidence', Perspectives on Psychological Science 10(4), pp. 518-536.

Lazarus, R.S. 1991. Emotion and Adaptation. New York: Oxford University Press.

Locke, J. [1690] 1997. An Essay Concerning Human Understanding. London: Penguin.

Mackie, J.L. [1977] 2011. Ethics: Inventing Right and Wrong. London: Penguin.

May, J. 2014. 'Does disgust influence moral judgment?', Australasian Journal of Philosophy 92(1), pp. 125-141.

McNaughton, D. 1988. Moral Vision: An Introduction to Ethics. Oxford: Blackwell.

Nussbaum, M.C. 2004. 'Emotions as judgments of value and importance', in: Solomon, R.C. (ed.): Thinking About Feeling: Contemporary Philosophers on Emotions. Oxford: Oxford University Press, pp. 183-199. 
Olson, J. 2014. Moral Error Theory: History, Critique, Defence. Oxford: Oxford University Press.

Pizarro, D., Inbar, Y., Helion, C. 2011. 'On disgust and moral judgment', Emotion Review $3(3), 267-268$.

Pölzler, T. 2014. Moral Reality and the Empirical Sciences. University of Graz: PhD Thesis.

Pölzler, T. 2015. 'Moral judgements and emotions: A less intimate relationship than recently claimed', Journal of Theoretical and Philosophical Psychology 35(3), pp. 177-195.

Pölzler, T. forthcoming. Revisiting folk moral realism. Manuscript under Review.

Prinz, J.J. 2006. 'The emotional basis of moral judgements', Philosophical Explorations 9(1), pp. 29-43.

Prinz, J.J. 2007. The Emotional Construction of Morals. Oxford: Oxford University Press.

Prinz, J.J. 2011. 'Sentimentalism and self-directed emotions', in: Konzelmann, A.Z., Lehrer, K. \& Schmid, H.B. (eds.). Self Evaluation: Affective and Social Grounds of Inten-tionality. Dordrecht: Springer, pp. 135-153.

Sarkissian, H., Tien, D., Wright, J. \& Knobe, J. 2011. 'Folk moral relativism', Mind and Language 26(4), pp. 482-505.

Schnall, S., Haidt, J., Clore, G.L. \& Jordan A.H. 2008a. 'Disgust as embodied moral judgment', Personality and Social Psychology Bulletin 34(8), pp. 1096-1109.

Schnall, S., Benton, J. \& Harvey, S. 2008b. 'With a clean conscience: Cleanliness reduces the severity of moral judgments', Psychological Science 19(12), pp. 1219-1222.

Smith, M. 1994. The Moral Problem. Oxford: Blackwell.

Solomon, R.C. 1993. The Passions: Emotions and the Meaning of Life. Indianapolis: Hackett.

Toplak, M.E., Stanovich, K.E. 2002. 'The domain specificity and generality of disjunctive reasoning: Searching for a generalizable critical thinking skill', Journal of Educational Psychology 94(1), pp. 197-209.

Wright, J.C., Grandjean, P.T. \& McWhite, C.B. 2013. 'The meta-ethical grounding of our moral beliefs: Evidence for meta-ethical pluralism', Philosophical Psychology 26(3), pp. 336-361.

Wright, J.C., McWhite, C.B., Grandjean, P.T. 2014. 'The cognitive mechanisms of intolerance: Do our meta-ethical commitments matter?', in: Knobe, J., Lombrozo, T. \& Nichols, 
S. (eds.). Oxford Studies in Experimental Philosophy, Vol. 1. Oxford: Oxford University Press, pp. 28-61. 